\title{
Metal Triflate-Promoted Allylic Substitution Reactions of Cinnamyl Alcohol in the Presence of Orthoesters and Acetals
}

\author{
Dawn R. Chaffey, ${ }^{\dagger}$ Carla Alamillo-Ferrer, ${ }^{\dagger}$ Thomas E. Davies, ${ }^{\S}$ Stuart H. Taylor, ${ }^{\S}$ \\ Nicholas C. O. Tomkinson, $\stackrel{\ddagger}{\ddagger}$ and Andrew E. Graham ${ }^{*} \dagger \odot$ \\ ${ }^{\dagger}$ School of Applied Sciences, University of South Wales, Pontypridd CF37 4AT, UK \\ ${ }^{\ddagger}$ WestCHEM, Department of Pure and Applied Chemistry, Thomas Graham Building, University of Strathclyde, Glasgow G1 1XL, \\ UK \\ ${ }^{\S}$ Cardiff Catalysis Institute, School of Chemistry, Cardiff University, Main Building, Park Place, Cardiff CF10 3AT, UK \\ Supporting Information
}

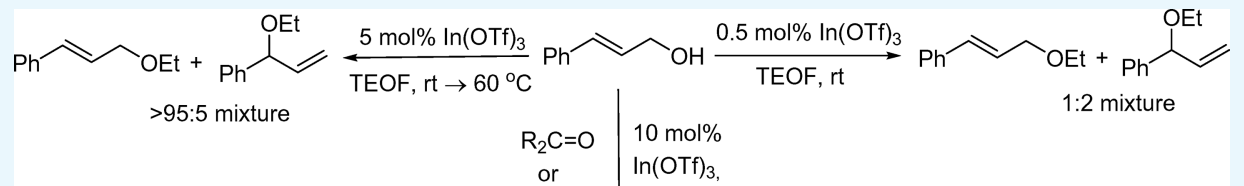

$$
\begin{aligned}
& \text { or } \quad \mathrm{ROH}, 40^{\circ} \\
& \overbrace{\sim 4: 1 \text { mixture }}^{\sim} \overbrace{\mathrm{OR}}^{\mathrm{OR}} \\
& \mathrm{R}=\mathrm{Me}, \mathrm{Et}, \mathrm{Pr},{ }^{\mathrm{i}} \mathrm{Pr}, \mathrm{Bu}
\end{aligned}
$$

ABSTRACT: The product distribution of ethers formed from the reaction of cinnamyl alcohol with orthoesters in the presence of indium (III) triflate (InOTf) $)_{3}$ is dependent on both the reaction temperature and catalyst loading. Carrying out the reaction at room temperature under low loadings of the catalyst leads to a facile reaction generating the unexpected secondary allyl ether as the major product. In contrast, carrying out the reaction under higher catalyst loadings at elevated temperatures provides the expected primary linear ether in high yield and with excellent selectivity. The etherification reaction is also effective in the presence of acetals and ketals in place of orthoesters and allows for the development of the procedure to encompass a telescoped etherification protocol in which the acetal is generated in situ.

\section{INTRODUCTION}

The continuing interest in the development of transition metal-catalyzed processes involving allylic substrates is testimony to the versatility and utility in this area of chemistry. Since the pioneering work of Tsuji and Trost, the scope of allylic substitution reactions has been expanded significantly and has developed into a powerful tool for the formation of carbon-carbon and carbon-heteroatom bonds, encompassing a range of nucleophiles, substrates, and metal catalysts. ${ }^{1,2}$ Furthermore, the extension of this reaction to encompass asymmetric variants is an area of significant current interest, and a number of recent reviews highlight the elegant developments and applications of this chemistry. ${ }^{3-6}$ In general, the majority of examples reported to date employ activated allylic substrates, which bear a good leaving group such as allylic esters, carbonates, or halides. ${ }^{7}$ Processes that employ allylic alcohols directly are not as widespread, although the recent recognition of the importance of waste minimization and the necessity for more benign and economical reaction processes has begun to address this imbalance. ${ }^{8,9}$ The synthesis of allyl ether products remains an area of considerable interest due to their diverse reactivity, which makes them highly versatile synthetic intermediates, particularly in natural product synthesis. ${ }^{10-13}$ While extensive work has demonstrated the facile reactions of carbon and nitrogen nucleophiles in transition metal-catalyzed allylic substitution reactions, the corresponding formation of carbon-oxygen bonds from both derivatized and underivatized allylic substrates remains a considerable challenge due to the low nucleophilicity of alcohols. ${ }^{14,15}$ Furthermore, the activation of alcohol substrates to nucleophilic substitution reactions has been identified as a key research area for further development within the pharmaceutical industry, ${ }^{16}$ and it is not surprising that there has been considerable interest in the development of methodology that produces ethers directly from alcohols without the requirement for strongly basic conditions or environmentally damaging alkylating agents (Scheme 1 and eqs $1-5)^{17-21}$

With this in mind, we were intrigued by the work of Kumar et al., who reported that cinnamyl alcohol $\mathbf{1}$ undergoes a nonselective reaction with triethyl orthoacetate (TEOAc) at elevated temperatures in the presence of a weakly acidic silicate

Received: July 5, 2019

Accepted: August 22, 2019

Published: September 23, 2019 
Scheme 1. Previous Etherification Strategies Employing Cinnamyl Alcohol (A-C)

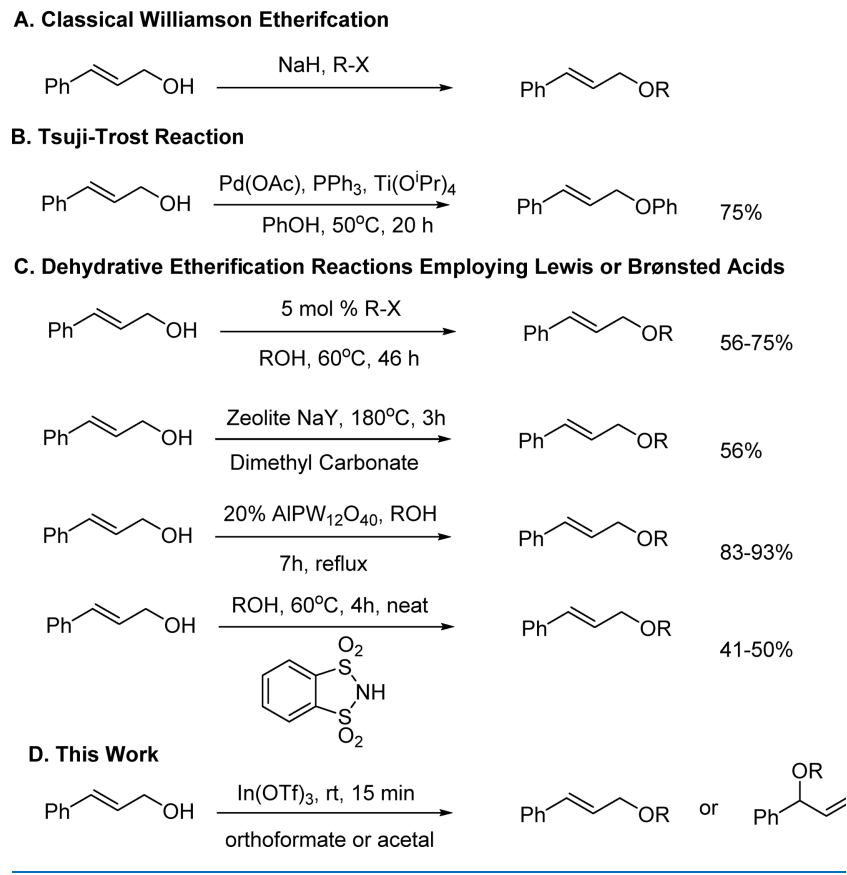

catalyst to produce a mixture of ether products $2 \mathbf{a}$ and $3 \mathbf{a}$ in a moderate yield, in addition to the quantities of products derived from dimerization 4 and acylation 5 (Scheme 2). ${ }^{22}$

The formation of significant quantities of the branched secondary ether product 3a observed here is also noteworthy, since these products are not generally observed in reactions employing linear primary allylic substrates except under highly specialized conditions such as in the case of iridium catalysis. $^{23,24}$ The direction of the equilibrium for allylic alcohols bearing phenyl substituents, such as $\mathbf{1}$, is dictated by thermodynamic considerations favoring the formation of the more conjugated linear products. ${ }^{21,25-27}$ Similarly, allylic substrates derived from the corresponding secondary alcohol typically give primary addition products as the major component of substitution reactions, except in special circumstances. ${ }^{14,28,29} \mathrm{We}$ were intrigued as to whether this orthoformate-mediated reaction could be developed to access an operationally simple allylic etherification protocol employing very mild reaction conditions, which would minimize isomerization and allow selective access to either the branched or linear ether products. Herein, we report our initial findings in this area, the extension of this methodology to the development of an acetal-mediated allylic etherificationreaction protocol, and our initial studies on the development of a catalytic process, which exploits the facile in situ generation of acetal and ketals.

\section{RESULTS AND DISCUSSION}

We reasoned that the reaction would be achieved more efficiently employing a catalyst that was sufficiently acidic to catalyze the etherification reaction but would not lead to significant isomerization of the ether products. Furthermore, this would also allow the use of reduced temperatures and hence minimize the corresponding thermal isomerization of the ether products. With this in mind, we considered a number of heterogeneous catalysts displaying a range of acidities to ascertain their effect on the etherification reaction of $\mathbf{1}$ in the presence of triethyl orthoformate (TEOF). Our preliminary studies employed nanoporous aluminosilicate materials, which we have previously demonstrated to be efficient catalysts for dehydrative etherification reaction at moderate temperatures. $^{30-32}$ Thus, the reaction of $\mathbf{1}$ with low loadings of the mildly acidic aluminosilicate catalyst Al-13-(3.18) (see Table $\mathrm{S} 1$ for catalyst properties) in the presence of stoichiometric quantities of TEOF at $60{ }^{\circ} \mathrm{C}$ resulted in good conversions of 1 and provided ether products $2 \mathbf{a}$ and $3 \mathbf{a}$ as a mixture of isomers $(2: 1)$, in addition to small quantities of dimer $4(\sim 10 \%)$ (Table 1 , entry 1$)$. Reducing the reaction temperature led to

Table 1. Nanoporous Aluminosilicate-Mediated Allylic Substitution Reactions of Cinnamyl Alcohol ${ }^{a}$

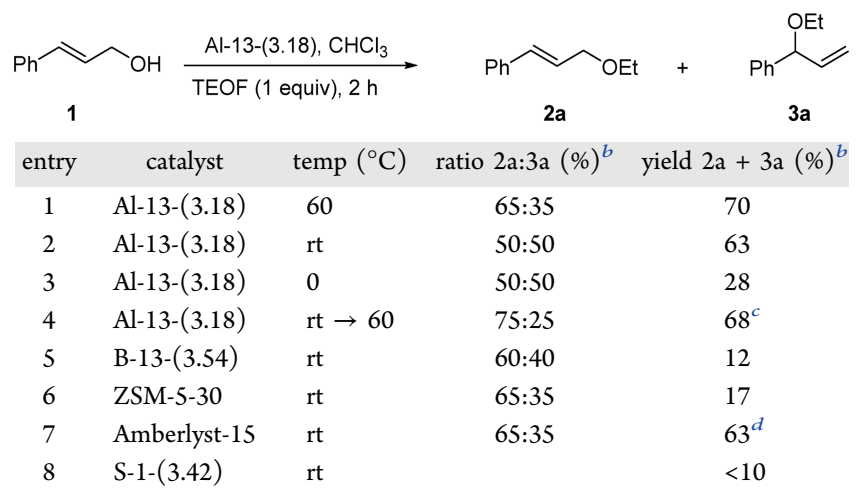

${ }^{a}$ Experimental conditions: the catalyst $(25 \mathrm{mg})$ was added to a solution of $1(0.5 \mathrm{mmol})$ and TEOF $(0.5 \mathrm{mmol})$ in chloroform (2 $\mathrm{mL})$ at the specified temperature. ${ }^{b}$ Determined by quantitative ${ }^{1} \mathrm{H}$ NMR spectroscopy and GC-MS analysis of the crude reaction mixture. ${ }^{c}$ Reaction heated to $60{ }^{\circ} \mathrm{C}$ for $1 \mathrm{~h}$ on completion of room temperature reaction. ${ }^{d}$ Reaction contains $10 \mathrm{mg}$ Amberlyst-15.

an increase in the quantities of $3 \mathbf{a}$ (1:1), suggesting that thermal isomerization may be an important factor in determining product ratios (entry 2). Reducing the temperature further to $0{ }^{\circ} \mathrm{C}$ gave little change in the ratio of isomers, however, overall yields were significantly reduced (entry 3 ).

In order to investigate the potential for thermal isomerization further, the crude reaction mixture from entry 2 was heated to $60{ }^{\circ} \mathrm{C}$ for an additional hour (entry 4). Analysis of this sample showed that the mixture now consisted predominantly of the linear ether $\mathbf{2 a}$, indicating that significant thermal isomerization had occurred. The large pore

Scheme 2. Reaction of Cinnamyl Alcohol in the Presence of TEOAc

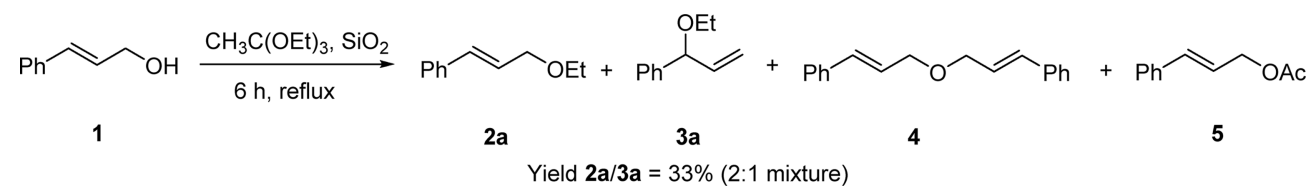


Table 2. Metal Triflate-Mediated Allylic Substitution Reactions of Cinnamyl Alcohol with Orthoesters ${ }^{a}$

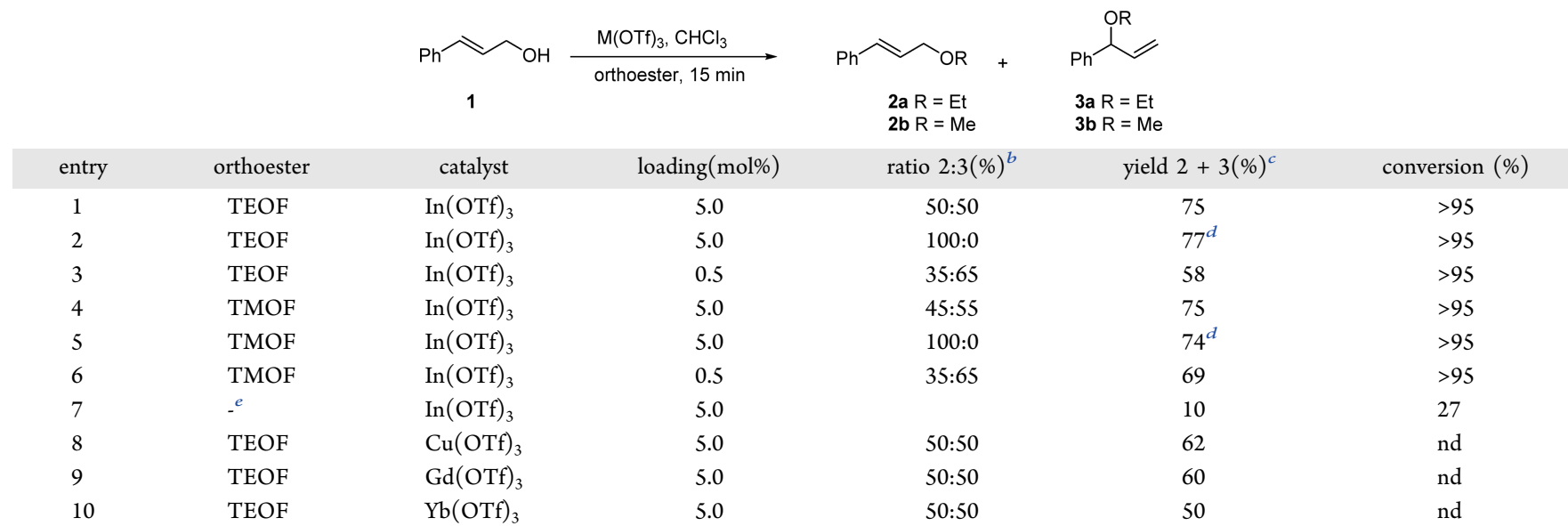

${ }^{a}$ Experimental conditions: The catalyst was added to a solution of $\mathbf{1}(0.5 \mathrm{mmol})$ and the specified orthoester $(0.5 \mathrm{mmol})$ in chloroform $(2 \mathrm{~mL})$ at room temperature. ${ }^{b}$ Determined by ${ }^{1} \mathrm{H}$ NMR spectroscopy. ${ }^{c}$ Combined yield of ether products 2 and 3 as determined by quantitative ${ }^{1} \mathrm{H}$ NMR spectroscopy of the crude reaction mixture. ${ }^{d}$ Reaction at room temperature for $15 \mathrm{~min}$ followed by heating to $60{ }^{\circ} \mathrm{C}$ for $15 \mathrm{~min}$. ${ }^{e} \mathrm{Reaction}$ contains 2 equiv of $\mathrm{MeOH}$.

borosilicate catalyst B-13-(3.54), ${ }^{33}$ which displays predominantly Lewis acidity, gave only low yields of ether products (entry 5), as did the use of the small pore zeolite ZSM-5-30 (entry 5). Improved yields were obtained on switching to Amberlyst-15, a strongly acidic macroreticular sulfonic acid resin with large pores, which gave a product distribution favoring linear ether 2a (entry 7). Reactions employing the plain silicate material S-1-(3.42), which displays very low acidity, gave no significant conversion to ether products at room temperature (entry 8 ).

These results highlight the importance of a judicious choice of catalyst and reaction temperature on the selectivity of the etherification of 1 , and while encouraged by these initial results, we recognize that further improvements in overall conversions and selectivity would not be possible with relatively weak acidic catalysts. Since the thermal sensitivity of 3a precludes the use of elevated temperatures to improve overall conversions, and to avoid extended reaction times at room temperature that could lead to equilibration under the conditions employed, we explored the use of strong Lewis acids to ascertain their potential as catalysts in this transformation. Metal triflate-catalyzed reactions are currently of significant recent interest, and they have found use as highly effective, environmentally benign, and water-tolerant catalysts. $^{34}$ Of particular interest has been the development of protocols employing indium(III) salts, and in particular, indium(III) triflate $\left(\operatorname{In}(\mathrm{OTf})_{3}\right)$, which has emerged as a highly flexible and chemoselective catalyst for a range of synthetic transformations. $^{35-37}$

Our initial reactions investigated the effect of catalyst loading on product distribution employing stoichiometric quantities of TEOF at room temperature. Under relatively high catalyst loadings of $\operatorname{In}(\mathrm{OTf})_{3}(5 \mathrm{~mol} \%)$, the reaction proceeded rapidly, giving approximately equal amounts of ether products $\mathbf{2 a}$ and $\mathbf{3 a}$ (Table 2, entry 1 ).

Subsequent heating of this reaction mixture to $60{ }^{\circ} \mathrm{C}$ led to complete thermal isomerization and selectively give the linear ether product $2 \mathrm{a}$ in high yields (entry 2). Decreasing the catalyst loading to $0.5 \mathrm{~mol} \%$ provided modest selectivity ( 2:1) for the branched ether product 3a (entry 3). Leaving the reaction for extended periods of time $(>18 \mathrm{~h})$ led to little change in the product ratios. At room temperature, we believe that the low catalyst loading employed is sufficient to catalyze formation of the branched ether product $3 a$, however, it is not sufficient to fully catalyze the subsequent isomerization to the thermodynamically more stable linear ether product 2a. A similar selectivity pattern was observed on switching from TEOF to TMOF, providing access to the methyl ether products $\mathbf{2 b}$ and $\mathbf{3 b}$ (entries $4-6$ ). These results compare very favorably with previous literature etherification protocols, giving high yields of ether products in very short reaction times and under much milder reaction conditions. ${ }^{17-21}$ Furthermore, the reaction is operationally simple, employing a commercially available catalyst and requiring no special precautions such as inert atmospheres or anhydrous conditions. Importantly, the reaction of $\mathbf{1}$ in the presence of $\mathrm{In}(\mathrm{OTf})_{3}$ and methanol in place of TMOF gave low yields of ether products even after extended reaction times $(>18 \mathrm{~h}$ ) (entry 7), as did the reaction of cinnamyl alcohol with TEOF in the absence of the catalyst. Replacing $\operatorname{In}(\mathrm{OTf})_{3}$ with other commercially available metal triflate salts gave broadly similar reaction profiles, albeit with reduced overall conversion to ether products (entries 8-10).

With an effective catalyst and conditions for the reaction identified, we next considered the reaction of cinnamyl alcohol with acetals and ketals in place of orthoester reagents. While the use of orthoesters provides a simple and effective process, an obvious limitation is the challenge of regenerating the orthoformate species in situ, limiting overall atom efficiency. We have recently demonstrated that dehydrative etherification reactions proceed efficiently in the presence of acetals and ketals, $^{32}$ an alternative approach that is highly attractive since the carbonyl by-product is far more versatile in terms of its potential to regenerate the acetal species under the reaction conditions (Scheme 3 ). Importantly, $\operatorname{In}(\mathrm{OTf})_{3}$ has previously been demonstrated to be a highly efficient catalyst for the generation of acetals and ketals ${ }^{38,39}$ and for transacetalization reactions, ${ }^{40-42}$ and provides significantly more opportunities for fine-tuning of the reactivity.

Our initial studies in this area considered the etherification reactions of $\mathbf{1}$ employing benzaldehyde dimethylacetal (BDMA) and dimethoxy propane (DMOP) in the presence 
Scheme 3. Potential Catalytic Cycle for the AcetalPromoted Allylic Etherification Reaction

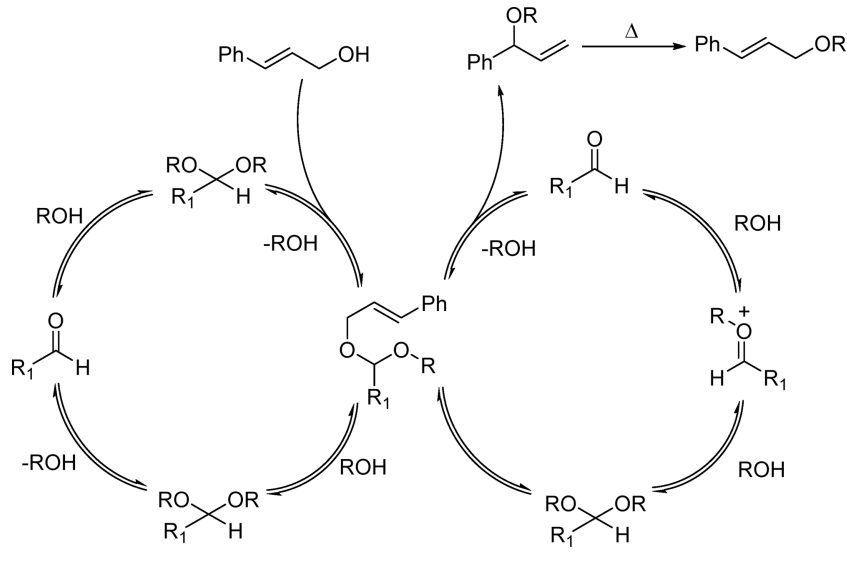

of $\operatorname{In}(\mathrm{OTf})_{3}$. We were gratified to observe that each of these reagents efficiently promoted the etherification reaction (Table 3). In the case of BDMA, overall yields were reduced in comparison to reactions employing orthoester (entries 1-3), reflecting the lower reactivity of BDMA in comparison to TEOF or TMOF, even in the presence of an excess of acetal (entry 4). Thermal isomerization was again successfully achieved on heating the final reaction mixtures to $60{ }^{\circ} \mathrm{C}$, which provided ether product $\mathbf{2} \mathbf{b}$ as the sole product with high selectivity (entry 5). Reactions employing DMOP proved more successful, and at higher catalyst loadings, provided ether products in moderate to good yields (entries 6-9). In this case, yields were increased on employing an excess of DMOP (entry 10), and were further improved on changing the reaction solvent to acetone, providing ether products in excellent yields (entry 11). The reaction process could also be extended to encompass the reaction of diethoxypropane (DEOP) to provide access to ether products $\mathbf{2 a}$ and $\mathbf{3 a}$, again in excellent yield (entry 12). Presumably, the increased reactivity of DMOP in comparison to BDMA facilitates rapid acetal exchange and promotes the etherification reaction.
Finally, we addressed the interesting possibility that the etherification process could be extended to utilize the ability of $\operatorname{In}(\mathrm{OTf})_{3}$ to generate the acetal or ketal species in situ from a carbonyl compound and an alcohol. There has been significant recent interest in the development of reaction sequences where multiple synthetic transformations are achieved without the isolation and purification of intermediates, as they offer considerable improvements in both efficiency and the overall atom efficiency. ${ }^{43,44}$ We have previously demonstrated that $\operatorname{In}(\mathrm{OTf})_{3}$ is a highly efficient catalyst for the in situ generation of acetals and their subsequent reaction, particularly where there is a significant difference in the reactivity of the acetal and the carbonyl species. ${ }^{45-47}$ With this in mind, we initially investigated two approaches by which the acetal species could be generated in situ. The first approach exploits the facile nature of the etherification reaction of $\mathbf{1}$ in acetone, which is used in a large excess to function both as a solvent and a reagent for acetal formation. We were gratified to observe that the etherification reaction proceeded smoothly in the presence of $10 \mathrm{~mol} \% \operatorname{In}(\mathrm{OTf})_{3}$, giving the corresponding ether products in good yields from a range of primary and secondary alcohols (Table 4; entries 1-6).

Finally, we investigated the in situ formation of acetals using stoichiometric quantities of aldehydes in the presence of In $(\mathrm{OTf})_{3}$ (Table 5). Reactions at room temperature in the presence of a small excess of methanol employing relatively low catalyst loadings $(5 \mathrm{~mol} \%)$ provided moderate yields of ether products, albeit over extended reaction times (entry 1 ). Switching to 4-anisaldehyde provided a small improvement in the overall yield, presumably reflecting the faster rate of formation of the acetal intermediate or the subsequent transacetalization reaction (entry 2). Heating the reaction reduced overall reaction times, and for reactions employing methanol at $40{ }^{\circ} \mathrm{C}$, good conversions of $\mathbf{1}$ to ether products $\mathbf{2 b}$ and $\mathbf{3 b}$ were achieved (entries 3 and 4 ). Reactions employing higher alcohols, however, proved more sluggish and required higher catalyst loadings to obtain moderate yields in acceptable reaction times (entries 5-9). As said previously, thermal isomerization was successfully achieved on heating the final

Table 3. In(OTf $)_{3}$ Mediated Etherification Reactions of Cinnamyl Alcohol in the Presence of Acetals and Ketals ${ }^{a}$

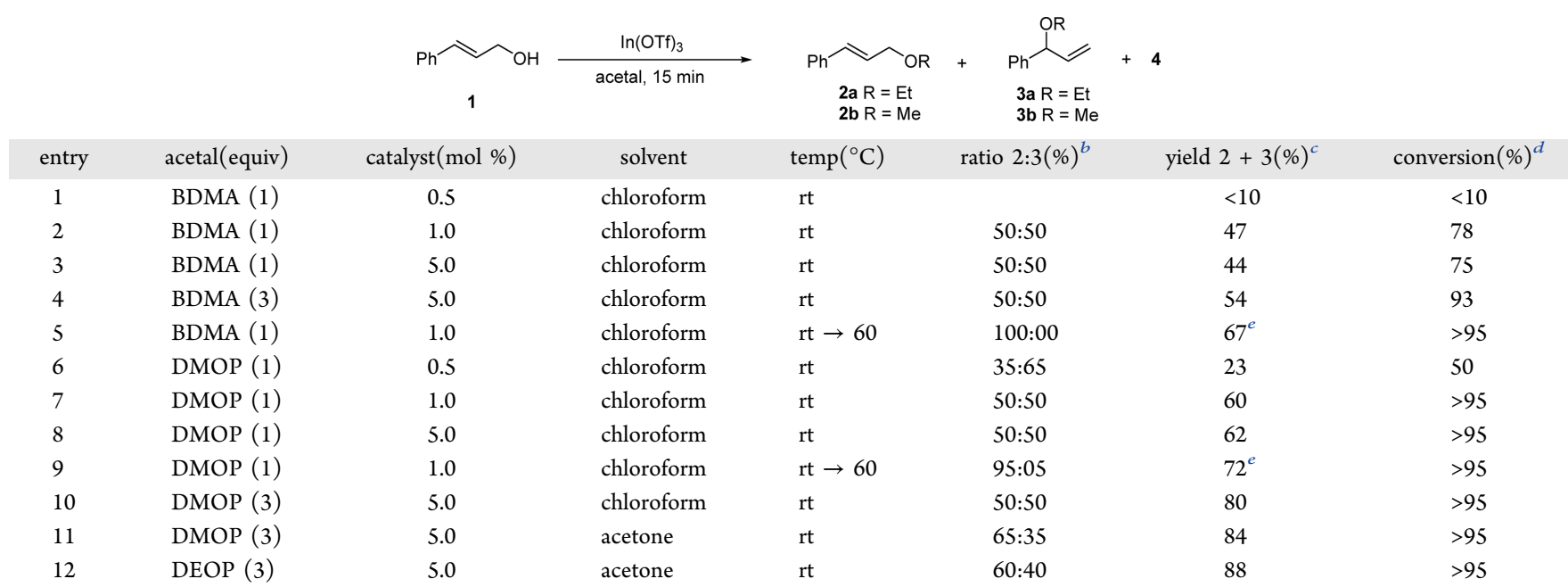

${ }^{a}$ Experimental conditions: $\operatorname{In}(\mathrm{OTf})_{3}$ was added to a solution of $\mathbf{1}(0.5 \mathrm{mmol})$ and the specified acetal in chloroform $(2 \mathrm{~mL}) .{ }^{b} \mathrm{Determined} \mathrm{by}{ }^{1} \mathrm{H}$ NMR spectroscopy and GC-MS analysis of the crude reaction mixture. ${ }^{c}$ Combined yield of ether products 2 and 3 as determined by quantitative ${ }^{1} \mathrm{H}$ NMR spectroscopy of the crude reaction mixture. ${ }^{d}$ Balance of material is symmetrical ether $4 .{ }^{e}$ Heated to $60{ }^{\circ} \mathrm{C}$ on completion of reaction for $15 \mathrm{~min}$. 
Table 4. In(OTf $)_{3}$-Mediated Etherification Reactions of Cinnamyl Alcohol in the Presence of Acetone

\begin{tabular}{|c|c|c|c|c|c|c|c|}
\hline & & $\mathrm{Ph} \leadsto$ & $\frac{\ln (\mathrm{OTf})_{3}, \text { Acetone }}{40^{\circ} \mathrm{C}, 4 \text { equiv } \mathrm{ROH}}$ & & $+\mathrm{Ph}_{3 \mathrm{a}-}$ & 4 & \\
\hline entry & $\mathrm{ROH}$ (equiv) & product & catalyst(mol \%) & time(h) & ratio $2: 3(\%)^{b}$ & yield $2+3(\%)^{c}$ & conversion $(\%)^{d}$ \\
\hline 1 & $\mathrm{EtOH}$ & $2 a / 3 a$ & 5 & 4 & $80: 20$ & 48 & 79 \\
\hline 2 & $\mathrm{EtOH}$ & $2 a / 3 a$ & 10 & 4 & $80: 20$ & 67 & 80 \\
\hline 3 & $\mathrm{MeOH}$ & $2 b / 3 b$ & 10 & 4 & $80: 20$ & 61 & 87 \\
\hline 4 & $\mathrm{PrOH}$ & $2 c / 3 c$ & 10 & 5 & $90: 10$ & 64 & 88 \\
\hline 5 & ${ }^{\mathrm{i}} \mathrm{PrOH}$ & $2 d / 3 d$ & 10 & 5 & $90: 10$ & 63 & 90 \\
\hline 6 & $\mathrm{BuOH}$ & $2 e / 3 e$ & 10 & 5 & $75: 15$ & 65 & 82 \\
\hline
\end{tabular}

${ }^{a}$ Experimental conditions: $\operatorname{In}(\mathrm{OTf})_{3}$ was added to a solution of $1(0.5 \mathrm{mmol})$ and the specified alcohol in acetone $(2 \mathrm{~mL})$ and heated at $40{ }^{\circ} \mathrm{C}$ for the specified time. ${ }^{b}$ Determined by quantitative ${ }^{1} \mathrm{H}$ NMR spectroscopy. ${ }^{c}$ Combined yield of ether products 2 and 3 as determined by quantitative ${ }^{1} \mathrm{H}$ NMR spectroscopy of the crude reaction mixture. ${ }^{d}$ Balance of material is symmetrical ether 4 .

Table 5. In(OTf $)_{3}$-Mediated Etherification Reactions of Cinnamyl Alcohol in the Presence of Aldehydes

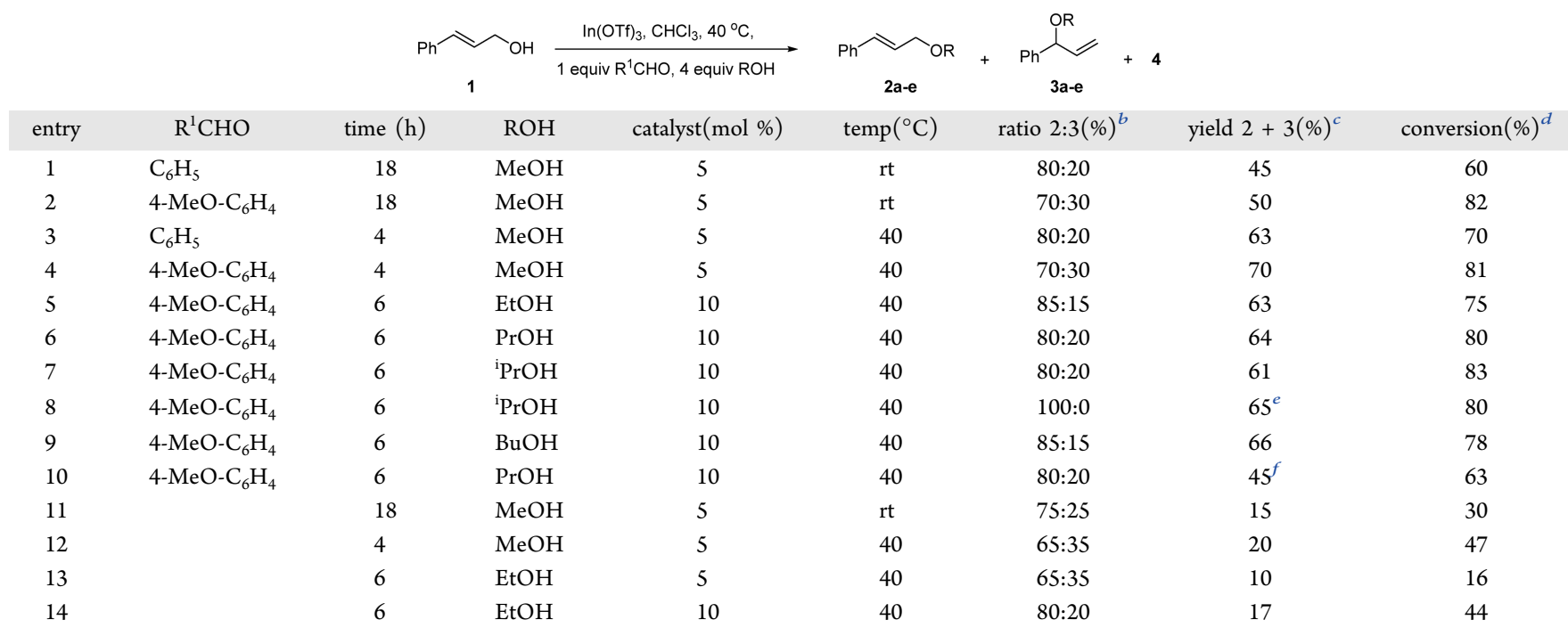

${ }^{a}$ Experimental conditions: $\operatorname{In}(\mathrm{OTf})_{3}$ was added to a solution of $1(0.5 \mathrm{mmol})$, the specified alcohol $(2 \mathrm{mmol})$, and aldehyde $(0.5 \mathrm{mmol})$ in chloroform $(2 \mathrm{~mL})$ at the specified temperature. ${ }^{b}$ Determined by ${ }^{1} \mathrm{H}$ NMR spectroscopy and GC-MS analysis of the crude reaction mixture. ${ }^{c}$ Combined yield of ether products 2 and 3 as determined by quantitative ${ }^{1} \mathrm{H}$ NMR spectroscopy of the crude reaction mixture. ${ }^{d}$ Balance of material is symmetrical ether $4 .{ }^{e}$ Heated to $60{ }^{\circ} \mathrm{C}$ on completion of reaction for 15 min. ${ }^{f_{\text {Reaction }}}$ contains 20 mol $\%$ of 4 -anisaldehyde.

reaction mixtures to $60{ }^{\circ} \mathrm{C}$, which provided the secondary ether product $\mathbf{2 d}$ with high selectivity (entry 8 ).

It also proved possible to obtain moderate yields of ether products in the presence of sub-stoichiometric quantities of aldehydes under these conditions. Reactions in the presence of $20 \mathrm{~mol} \%$ of 4 -anisaldehyde proceeded to give yields similar to those employing stoichiometric quantities, offering support for the catalytic nature of the acetal in these reactions (entry 10). Consistent with previous results, yields of ether products were significantly lower in the absence of aldehyde, (entries 11-14).

\section{CONCLUSIONS}

In conclusion, we have demonstrated that low loadings of In(OTf $)_{3}$ catalyze the allylic substitution reactions of cinnamyl alcohol in the presence of orthoesters to produce the branched allyl ethers as the major products in very short reaction times. The product distribution of the reaction is easily reversed to provide the corresponding linear ethers by employing higher catalyst loadings, or can be achieved selectively at elevated temperatures. We have also demonstrated that etherification proceeds in the presence of acetals and ketals, which also efficiently promotes the etherification reactions of cinnamyl alcohol. In the case of BDMA, this reaction proceeds more slowly than in the presence of orthoesters, requiring longer reaction times, and reflects the increased stability of the acetal. Ketals, such as DMOP, display broadly similar reactivity patterns to orthoesters providing the branched allyl ether products at low catalyst loadings. This protocol can be further extended to encompass a telescoped protocol in which the acetal is generated in situ from an aldehyde or ketone and a small excess of alcohol in the presence of $\operatorname{In}(\mathrm{OTf})_{3}$.

\section{EXPERIMENTAL SECTION}

Materials and Methods. Commercially available materials were used as received. Alcohol solvents were dried and stored over activated $3 \AA$ molecular sieves prior to use. Nanoporous aluminosilicate catalysts were prepared as described previously and stored at $140{ }^{\circ} \mathrm{C}$ for at least $12 \mathrm{~h}$ prior to use as was ZSM5-30. Amberlyst-15 was dried overnight under vacuum. All reactions were carried out in a sealed batch reactor. Product mixtures were analyzed using ${ }^{1} \mathrm{H}$ NMR spectroscopy and GCMS. Percentage yields, percentage conversions, and selectivity were determined using quantitative ${ }^{1} \mathrm{H}$ NMR spectroscopy employing para-xylene by integration of the relevant signals. 
GC-MS analysis was performed in EI mode using a Varian 450GC and Varian 300MS employing a VF-5 ms capillary column $(30 \mathrm{~m}, 0.25 \mathrm{~mm}$ i.d., and $0.25 \mu \mathrm{m})$ operating with a gradient temperature profile with an initial temperature of 50 ${ }^{\circ} \mathrm{C}$ for 3 min rising to $280{ }^{\circ} \mathrm{C}$ at a rate of $20^{\circ} \mathrm{C} \mathrm{min}{ }^{-1}$ followed by a $3 \mathrm{~min}$ hold time. All products gave spectroscopic data consistent with previous literature reports. ${ }^{21,28,29,48}$

Typical Procedure for the Allylic Substitution Reaction of Cinnamyl Alcohol with TEOF. Indium triflate (14 mg, $0.025 \mathrm{mmol}, 5 \mathrm{~mol} \%$ ) was added to a solution of cinnamyl alcohol (67 mg, $0.5 \mathrm{mmol}$ ) and TEOF (75 mg, 0.5 $\mathrm{mmol})$ in chloroform $(2 \mathrm{~mL})$ at room temperature and stirred for $15 \mathrm{~min}$. On completion of the reaction, the crude reaction mixture was analyzed by quantitative ${ }^{1} \mathrm{H}$ NMR spectroscopy and GC-MS analysis giving a 75\% yield of ethers $2 a$ and $3 a$ as a mixture of isomers (50:50). Subsequent heating of this reaction mixture at $60{ }^{\circ} \mathrm{C}$ for $15 \mathrm{~min}$ gave $2 \mathrm{a}(77 \%)$.

Typical Procedure for the Allylic Substitution Reaction of Cinnamyl Alcohol with BDMA. Indium triflate (14 mg, $0.025 \mathrm{mmol}, 5 \mathrm{~mol} \%$ ) was added to a solution of cinnamyl alcohol (67 mg, $0.5 \mathrm{mmol})$ and benzaldehyde dimethyl acetal $(76 \mathrm{mg}, 0.5 \mathrm{mmol})$ in chloroform $(2 \mathrm{~mL})$ at room temperature and stirred for $1 \mathrm{~h}$. On completion of the reaction, the crude reaction mixture was analyzed by quantitative ${ }^{1} \mathrm{H}$ NMR spectroscopy and GC-MS analysis giving a $67 \%$ yield of ethers $2 \mathbf{b}$ and $\mathbf{3 b}$ as mixture of isomers (80:20).

Typical Procedure for the Telescoped Allylic Substitution Reaction of Cinnamyl Alcohol Employing Stoichiometric Quantities of Anisaldehyde. Indium triflate (28 mg, $0.05 \mathrm{mmol}, 10 \mathrm{~mol} \%)$ was added to a solution of cinnamyl alcohol (67 mg, $0.5 \mathrm{mmol})$, ethanol (92 $\mathrm{mg}, 2 \mathrm{mmol})$, and anisaldehyde (68 $\mathrm{mg}, 0.5 \mathrm{mmol})$ in chloroform $(2 \mathrm{~mL})$ and stirred at $40{ }^{\circ} \mathrm{C}$ for $6 \mathrm{~h}$. On completion of the reaction, the reaction mixture was analyzed by quantitative ${ }^{1} \mathrm{H}$ NMR spectroscopy and GC-MS analysis giving a $63 \%$ yield of ethers $2 \mathbf{a}$ and $3 a$ as mixture of isomers (85:15).

\section{ASSOCIATED CONTENT}

\section{(5) Supporting Information}

The Supporting Information is available free of charge on the ACS Publications website at DOI: 10.1021/acsomega.9b02059.

General methods, aluminosilicate catalyst characterization, catalyst physical properties, and GC-MS and NMR data (PDF)

\section{AUTHOR INFORMATION}

\section{Corresponding Author}

*E-mail: andrew.graham@southwales.ac.uk.

\section{ORCID}

Stuart H. Taylor: 0000-0002-1933-4874

Nicholas C. O. Tomkinson: 0000-0002-5509-0133

Andrew E. Graham: 0000-0002-2761-5967

Notes

The authors declare no competing financial interest.

\section{ACKNOWLEDGMENTS}

N.C.O.T. and C.A.-F. thank the University of Strathclyde (CAF) for financial support.

\section{REFERENCES}

(1) Trost, B. M. New Rules of Selectivity: Allylic Alkylations Catalyzed by Palladium. Acc. Chem. Res. 1980, 13, 385-393.

(2) Tsuji, J. Pd(0)-Catalyzed Reactions of Allylic Compounds via $\pi$ Allylpalladium Complexes. In Palladium Reagents and Catalysts: New Perspectives for the 21st Century; Tsuji, J., Ed.; John Wiley \& Sons Ltd: Chichester, 2004.

(3) Lu, Z.; Ma, S. Angew Chem., Int. Ed. 2008, 47, 258-297.

(4) Trost, B. M.; Crawley, M. L. Asymmetric transition-metalcatalyzed allylic alkylations: applications in total synthesis. Chem. Rev. 2003, 103, 2921-2944.

(5) Trost, B. M.; Zhang, T.; Sieber, J. D. Catalytic asymmetric allylic alkylation employing heteroatom nucleophiles: a powerful method for C-X bond formation. Chem. Sci. 2010, 1, 427-440.

(6) Trost, B. M.; Van Vranken, D. L. Asymmetric transition metalcatalyzed allylic alkylations. Chem. Rev. 1996, 96, 395-422.

(7) Muzart, J. Palladium-catalysed reactions of alcohols. Part B: Formation of $\mathrm{C}-\mathrm{C}$ and $\mathrm{C}-\mathrm{N}$ bonds from unsaturated alcohols. Tetrahedron 2005, 61, 4179-4212.

(8) Butt, N. A.; Zhang, W. Transition metal-catalyzed allylic substitution reactions with unactivated allylic substrates. Chem. Soc. Rev. 2015, 44, 7929-7967.

(9) Sundararaju, B.; Achard, M.; Bruneau, C. Transition metal catalyzed nucleophilic allylic substitution: activation of allylic alcohols via $\pi$-allylic species. Chem. Soc. Rev. 2012, 41, 4467-4483.

(10) Evans, P. A.; Leahy, D. K.; Andrews, W. J.; Uraguchi, D. Stereodivergent construction of cyclic ethers by a regioselective and enantiospecific rhodium-catalyzed allylic etherification: total synthesis of gaur acid. Angew. Chem., Int. Ed. 2004, 43, 4788-4791.

(11) Lumbroso, A.; Cooke, M. L.; Breit, B. Catalytic asymmetric synthesis of allylic alcohols and derivatives and their applications in organic synthesis. Angew. Chem., Int. Ed. 2013, 52, 1890-1932.

(12) Trost, B. M.; Crawley, M. L. 4-Aryloxybutenolides as "chiral aldehyde" equivalents: an efficient enantioselective synthesis of (+)-brefeldin A. J. Am. Chem. Soc. 2002, 124, 9328-9329.

(13) Trost, B. M.; Gunzner, J. L.; Dirat, O.; Rhee, Y. H. Callipeltoside A: total synthesis, assignment of the absolute and relative configuration, and evaluation of synthetic analogues. J. Am. Chem. Soc. 2002, 124, 10396-10415.

(14) Mukherjee, P.; Widenhoefer, R. A. The regio- and stereospecific intermolecular dehydrative alkoxylation of allylic alcohols catalyzed by a gold(I) $N$-heterocyclic carbene complex. Chem. - Eur. J. 2013, 19, 3437-3444.

(15) Young, P. C.; Schopf, N. A.; Lee, A.-L. Gold(I)-catalysed direct allylic etherification of unactivated alcohols. Chem. Commun. 2013, 49, 4262-4264.

(16) Constable, D. J. C.; Dunn, P. J.; Hayler, J. D.; Humphrey, G. R.; Leazer, J. L., Jr.; Linderman, R. J.; Lorenz, K.; Manley, J.; Pearlman, B. A.; Wells, A.; Zaks, A.; Zhang, T. Y. Key green chemistry research areas-a perspective from pharmaceutical manufacturers. Green Chem. 2007, 9, 411-420.

(17) Satoh, T.; Ikeda, M.; Miura, M.; Nomura, M. Palladiumcatalyzed etherification of allyl alcohols using phenols in the presence of titanium(IV) isopropoxide. J. Org. Chem. 1997, 62, 4877-4879.

(18) Xu, Q.; Xie, H.; Chen, P.; Yu, L.; Chen, J.; Hu, X. Organohalide-catalyzed dehydrative $\mathrm{O}$-alkylation between alcohols: a facile etherification method for aliphatic ether synthesis. Green Chem. 2015, 17, 2774-2779.

(19) Stanley, J. N. G.; Selva, M.; Masters, A. F.; Maschmeyer, T.; Perosa, A. Reactions of $p$-coumaryl alcohol model compounds with dimethyl carbonate. Towards the upgrading of lignin building blocks. Green Chem. 2013, 15, 3195-3204.

(20) Firouzabadi, H.; Iranpoor, N.; Jafari, A. A. Facile preparation of symmetrical and unsymmetrical ethers from their corresponding alcohols catalyzed by aluminumdodecatangstophosphate $\left(\mathrm{AlPW}_{12} \mathrm{O}_{40}\right)$, as a versatile and a highly water tolerant Lewis acid. J. Mol. Catal. A: Chem. 2005, 227, 97-100. 
(21) Barbero, M.; Cadamuro, S.; Dughera, S.; Venturello, P. oBenzenedisulfonimide as reusable Brønsted acid catalyst for acidcatalyzed organic reactions. Synthesis 2008, 1379-1388.

(22) Kumar, H. M. S.; Joyasawal, S.; Reddy, B. V. S.; Chakravarthy, P. P.; Krishna, A. D.; Yadav, J. S. Reaction of orthoesters with alcohols in the presence of acidic catalysts: a study. Indian J. Chem. B 2005, 44, $1686-1692$.

(23) Ueno, S.; Hartwig, J. F. Direct, iridium-catalyzed enantioselective and regioselective allylic etherification with aliphatic alcohols. Angew. Chem., Int. Ed. 2008, 47, 1928-1931.

(24) Shu, C.; Hartwig, J. F. Iridium-catalyzed intermolecular allylic etherification with aliphatic alkoxides: asymmetric synthesis of dihydropyrans and dihydrofurans. Angew. Chem., Int. Ed. 2004, 43, 4794-4797.

(25) Morrill, C.; Grubbs, R. H. Highly selective 1,3-isomerization of allylic alcohols via rhenium oxo catalysis. J. Am. Chem. Soc. 2005, 127, 2842-2843.

(26) Jacob, J.; Espenson, J. H.; Jensen, J. H.; Gordon, M. S. 1,3Transposition of allylic alcohols catalyzed by methyltrioxorhenium. Organometallics 1998, 17, 1835-1840.

(27) Haight, A. R.; Stoner, E. J.; Peterson, M. J.; Grover, V. K. General method for the palladium-catalyzed allylation of aliphatic alcohols. J. Org. Chem. 2003, 68, 8092-8096.

(28) Roggen, M.; Carreira, E. M. Enantioselective allylic etherification: selective coupling of two unactivated alcohols. Angew. Chem., Int. Ed. 2011, 50, 5568-5571.

(29) Shinozawa, T.; Terasaki, S.; Mizuno, S.; Kawatsura, M. Kinetic resolution of racemic and branched monosubstituted allylic acetates by a ruthenium-catalyzed regioselective allylic etherification. J. Org. Chem. 2016, 81, 5766-5774.

(30) Davies, T. E.; Kean, J. R.; Apperley, D. C.; Taylor, S. H.; Graham, A. E. Nanoporous aluminosilicate-mediated synthesis of ethers by a dehydrative etherification approach. ACS Sustainable Chem. Eng. 2014, 2, 860-866.

(31) Davies, T. E.; Kean, J. R.; Apperley, D. C.; Taylor, S. H.; Graham, A. E. Dehydrative etherification reactions of glycerol with alcohols catalyzed by recyclable nanoprous aluminosilicates: telescoped routes to glyceryl ethers. ACS Sustainable Chem. Eng. 2016, 4, $835-843$.

(32) Chaffey, D. R.; Davies, T. E.; Taylor, S. H.; Graham, A. E. Etherification reactions of furfuryl alcohol in the presence of Orthoesters and ketals: application to the synthesis of furfuryl ether Biofuels. ACS Sustainable Chem. Eng. 2018, 6, 4996-5002.

(33) Davies, T. E.; Kondrat, S. A.; Nowicka, E.; Kean, J. L.; Harris, C. M.; Socci, J. M.; Apperley, D. C.; Taylor, S. H.; Graham, A. E. Nanoporous alumino- and borosilicate-mediated Meinwald rearrangement of epoxides. Appl. Catal., A 2015, 493, 17-24.

(34) Kobayashi, S.; Sugiura, M.; Kitagawa, H.; Lam, W. W. L. Rareearth metal triflates in organic synthesis. Chem. Rev. 2002, 102, 22272302.

(35) Frost, C.; Hartley, J. New applications of indium catalysts in organic synthesis. Mini-Rev. Org. Chem. 2004, 1, 1-7.

(36) Fringuelli, F.; Piermatti, O.; Pizzo, F.; Vaccaro, L. Indium saltpromoted organic reactions. Curr. Org. Chem. 2003, 7, 1661-1689.

(37) For the $\operatorname{In}(\mathrm{OTf})$ mediated etherification and hydrolysis of furfuryl alcohol see: Kean, J. R.; Graham, A. E. Indium(III) triflate promoted synthesis of alkyl levulinates from furyl alcohols and furyl aldehydes. Catal. Commun. 2015, 59, 175-179.

(38) Gregg, B. T.; Golden, K. C.; Quinn, J. F. Indium(III)trifluoromethanesulfonate as a mild, efficient catalyst for the formation of acetals and ketals in the presence of acid sensitive functional groups. Tetrahedron 2008, 64, 3287-3295.

(39) Smith, B. M.; Graham, A. E. Indium triflate mediated acetalization of aldehydes and ketones. Tetrahedron Lett. 2006, 47, 9317-9319.

(40) Smith, B. M.; Graham, A. E. Indium triflate mediated tandem acetalisation-acetal exchange reactions under solvent-free conditions. Tetrahedron Lett. 2011, 52, 6281-6283.
(41) Smith, B. M.; Kubczyk, T. M.; Graham, A. E. Indium(III) triflate catalysed transacetalisation reactions of diols and triols under solvent-free conditions. Tetrahedron 2012, 68, 7775-7781.

(42) Smith, B. M.; Kubczyk, T. M.; Graham, A. E. Metal triflate catalysed acetal exchange reactions of glycerol under solvent-free conditions. RSC Adv. 2012, 2, 2702-2706.

(43) Tietze, L. F. Domino reactions in organic synthesis. Chem. Rev. 1996, 96, 115-136.

(44) Hayashi, Y. Pot economy and one-pot synthesis. Chem. Sci. 2016, 7, 866-880.

(45) Smith, B. M.; Graham, A. E. Sequential and tandem oxidation/ acetalization procedures for the direct generation of acetals from alcohols. Tetrahedron Lett. 2007, 48, 4891-4894.

(46) Kubczyk, T. M.; Williams, S. M.; Kean, J. R.; Davies, T. E.; Taylor, S. H.; Graham, A. E. Nanoporous aluminosilicate catalyzed Friedel-Crafts alkylation reactions of indoles with aldehydes and acetals. Green Chem. 2011, 13, 2320-2325.

(47) Davies, T. E.; Taylor, S. H.; Graham, A. E. Nanoporous aluminosilicate-catalyzed telescoped acetalization-direct aldol reactions of acetals with 1,3-dicarbonyl compounds. ACS Omega 2018, 3, $15482-15491$.

(48) Kasashima, Y.; Uzawa, A.; Hashimoto, K.; Nishida, T.; Murakami, K.; Mino, T.; Sakamoto, M.; Fujita, T. Synthesis of cinnamyl ethers from.ALPHA.-Vinylbenzyl alcohol using iodine as catalyst. J. Oleo Sci. 2010, 59, 549-555. 